\title{
$\left[{ }^{13} \mathrm{C}\right]$ Glucose Breath Testing Provides a Noninvasive Measure of Insulin Resistance: Calibration Analyses Against Clamp Studies
}

\author{
Maysa Hussain, MD, Morteza Jangorbhani, PhD, ${ }^{2,3}$ Sally Schuette, ${ }^{2}$ Robert V. Considine, PhD, \\ Robin L. Chisholm, and Kieren J. Mather, MD, FRCPC ${ }^{1}$
}

\begin{abstract}
Background: Exhaled ${ }^{13} \mathrm{CO}_{2}$ following ingestion of $\left[{ }^{13} \mathrm{C}\right]$ glucose with a standard oral glucose tolerance load correlates with blood glucose values but is determined by tissue glucose uptake. Therefore exhaled ${ }^{13} \mathrm{CO}_{2}$ may also be a surrogate measure of the whole-body glucose disposal rate (GDR) measured by the gold standard hyperinsulinemic euglycemic clamp.

Subjects and Methods: Subjects from across the glycemia range were studied on 2 consecutive days under fasting conditions. On Day 1, a 75-g oral glucose load spiked with $\left[{ }^{13} \mathrm{C}\right]$ glucose was administered. On Day 2, a hyperinsulinemic euglycemic clamp was performed. Correlations between breath parameters and clamp-derived GDR were evaluated, and calibration analyses were performed to evaluate the precision of breath parameter predictions of clamp measures.

Results: Correlations of breath parameters with GDR and GDR per kilogram of fat-free mass (GDR ffm) ranged from 0.54 to 0.61 and 0.54 to 0.66 , respectively (all $P<0.001$ ). In calibration analyses the root mean square error for breath parameters predicting GDR and $\mathrm{GDR}_{\mathrm{ffm}}$ ranged from 2.32 to 2.46 and from 3.23 to 3.51, respectively. Cross-validation prediction error (CVPE) estimates were 2.35-2.51 (GDR) and 3.29-3.57 (GDR $\left.\mathrm{ffm}_{\mathrm{m}}\right)$. Prediction precision of breath enrichment at $180 \mathrm{~min}$ predicting GDR $(\mathrm{CVPE}=2.35)$ was superior to that for inverse insulin (2.68) and the Matsuda Index (2.51) but inferior to that for the log of homeostasis model assessment $(2.21)$ and Quantitative Insulin Sensitivity Check Index $(2.29)\left(\right.$ all $\left.P<10^{-5}\right)$. Similar patterns were seen for predictions of $\mathrm{GDR}_{\mathrm{ffm}}$.

Conclusions: ${ }^{13} \mathrm{CO}_{2}$ appearance in exhaled breath following a standard oral glucose load with added [ $\left.{ }^{13} \mathrm{C}\right] \mathrm{glucose}$ provides a valid surrogate index of clamp-derived measures of whole-body insulin resistance, with good accuracy and precision. This noninvasive breath test-based approach can provide a useful measure of whole-body insulin resistance in physiologic and epidemiologic studies.
\end{abstract}

\section{Introduction}

$\mathbf{T}$ HE EPIDEMIOLOGIC IMPORTANCE of insulin resistance is increasingly recognized. However, measurement of insulin resistance remains problematic. Although the gold standard measurement approach using the euglycemic hyperinsulimemic clamp procedure ${ }^{1}$ is well established, this method is labor-intensive and requires the availability of specialized personnel and facilities. With this in mind, several surrogate indices of insulin resistance have been developed and refined, including, among others, the homeostasis model (HOMA) of insulin resistance (HOMA-IR) ${ }^{2-4}$ the Quantitative Insulin Sensitivity Check Index (QUICKI), ${ }^{5}$ and the Matsuda Index. ${ }^{6}$ These parameters all correlate strongly with clamp-derived measures of whole-body insulin resistance. ${ }^{5,7-11}$
The ease of acquiring the required measurements, combined with the good accuracy and precision of prediction for $\operatorname{logHOMA-IR}$ and QUICKI when calibrated against formal measures, ${ }^{12}$ supports the broad use of these fasting indices as surrogate measures of insulin resistance in epidemiologic and physiologic studies. Calibration analyses of the accuracy and precision of the Matsuda Index have not been previously published.

Fasting insulin and glucose measurements reflect different metabolic physiology than dynamic tests. In particular, the response to and disposition of an oral glucose load provide information about $\beta$-cell response and insulin action that is not captured with fasting samples alone. Here we have assessed a wholly noninvasive oral glucose tolerance test (OGTT)-based breath test ${ }^{13-16}$ as an alternative index of insulin resistance.

\footnotetext{
${ }^{1}$ Indiana University School of Medicine, Indianapolis, Indiana.

${ }^{2}$ BioChem Analysis Inc., Chicago, Illinois.

${ }^{3}$ Center for Stable Isotope Research, Inc., Chicago, Illinois.
} 
Under this approach, a small amount of commercially available $\left[{ }^{13} \mathrm{C}\right]$ glucose is added to a standard 75-g oral glucose load. The subsequent appearance of $\left[{ }^{13} \mathrm{C} \mathrm{CO}_{2}\right.$ in breath requires that the ingested glucose undergo cellular metabolism, and therefore this measurement integrates glucose absorption, the glucoseinduced insulin response, and tissue uptake of glucose as precursors to cellular metabolism. Therefore this breath test is likely to provide a measurement of whole-body insulin response, which is conceptually quite different from indices derived only from fasting measures. Only one prior study has been published evaluating the relationships between ${ }^{13} \mathrm{C}$ breath data and the glucose clamp, ${ }^{17}$ and calibration analyses have not previously been performed for these tests. Therefore we have undertaken studies exploring these relationships to better inform the application of breath testing to epidemiologic and physiologic testing of metabolism.

\section{Subjects and Methods}

\section{Subject recruitment, screening, and preparation}

We recruited by local advertising a cohort of men and women, 18-65 years of age. The goal of recruitment was to have a set of subjects representative of the full spectrum of glycemia, to maximize representativeness and validity of comparisons against clamp measures. At the time of enrollment subjects were categorized as lean (body mass index $\leq 25 \mathrm{~kg} / \mathrm{m}^{2}$ ), overweight (body mass index $25-30 \mathrm{~kg} / \mathrm{m}^{2}$ noninclusive), or obese (body mass index $\geq 30 \mathrm{~kg} / \mathrm{m}^{2}$ ). Diabetes mellitus could be by prior physician diagnosis or defined as part of screening procedures when volunteers underwent a screening 2-h 75-g OGTT under fasting conditions (applying American Diabetes Association criteria of fasting glucose level of $>126 \mathrm{mg} / \mathrm{dL}$ or 2 -h glucose level after a 75-g OGTT of $>200 \mathrm{mg} / \mathrm{dL}$ ). Participants with diabetes were treated with any combination of diet, exercise, insulin, or antidiabetes medications except insulin-sensitizing agents. Use of thiazolidinediones within 6 months or metformin within 4 weeks was an exclusion criterion, as these agents systematically affect hepatic and peripheral insulin sensitivity and may have influenced our study by modifying the underlying relationships between insulin secretion and insulin responses. Stable antihypertensive or antihyperlipidemic medications were allowed. Subjects were excluded if not weight-stable for at least 6 months, if they had type 1 disease or rare variant forms of diabetes, were pregnant, had a concurrent acute or chronic medical illness likely to affect systemic fuel metabolism, used psychotropic medication including an antidepressant, or had pulmonary disease or a history of current or past smoking.

Subjects initially underwent screening evaluation, including a standard 75-g OGTT and routine blood testing evaluating possible hematologic or biochemical evidence for underlying disease. Body composition was measured by dual energy x-ray absorptiometry at the time of screening evaluation. Subjects who qualified from screening and consented to participate were scheduled for clinical research center admission on 2 consecutive days to undergo study measurements.

\section{Measurements}

All studies were done in the morning following an overnight fast; subjects consumed their usual diet except where provided by the study while admitted to the clinical research center. Subjects were admitted to the Indiana Clinical Translational Sciences Institute Clinical Research Center for the 2-day duration of these studies. Subjects with diabetes continued to take their antidiabetes treatments, except morning treatments were withheld on each of the 2 measurement days until after the completion of the studies.

Anthropomorphic and blood pressure measures were performed the morning of the first testing procedure. Beginning at 7:30 a.m., baseline blood samples were drawn through an indwelling intravenous catheter, followed by a standard 75 -g OGTT containing an added $150 \mathrm{mg}$ of $\left[{ }^{13} \mathrm{C}_{6}\right]$ glucose (catalog number CLM-1396; Cambridge Isotope Laboratories, Andover, MA). Breath samples were obtained at half-hourly intervals during the following $3 \mathrm{~h}$. Blood samples were obtained concurrent with these breath samples. Upon completion of the OGTT, subjects were fed lunch and dinner ad libitum. Fasting from 8 p.m. was again implemented in anticipation of the second measurement day.

A 4-h hyperinsulinemic euglycemic clamp procedure was performed on the second day using established procedures in our laboratory, ${ }^{18,19}$ based on the original method of DeFronzo et al. ${ }^{1}$ A catheter was placed on the dorsum of the nondominant hand, which was warmed continuously for sampling of arterialized venous blood. An insulin infusion rate of $120 \mathrm{mU} / \mathrm{m}^{2} / \mathrm{min}$ was used, to ensure full suppression of endogenous (hepatic) glucose production in all subject populations. ${ }^{20-22}$ Blood samples were withdrawn from the arterialized hand line at 5-min intervals throughout and measured immediately using a glucose oxidase method with high precision (YSI 2500 STAT glucose analyzer; Yellow Springs Instruments, Yellow Springs, OH). A continuous infusion of $20 \mathrm{mg} / 100 \mathrm{~mL}$ of dextrose was adjusted to maintain the arterialized glucose level at $90 \pm 4 \mathrm{mg} / \mathrm{dL}$. Upon completion of the Hour 4 measurements, subjects were fed lunch, and the glucose infusion was then tapered to off in 30-min intervals over the subsequent $3 \mathrm{~h}$.

\section{Analytical procedures}

Breath $\left[{ }^{13} \mathrm{C}\right]$ glucose enrichment was measured using isotope ratio mass spectrometry (Metabolic Solutions, Nashua, $\mathrm{NH})$. Screening laboratory measurements were performed by the Indiana University Health clinical laboratory using standard methodologies. Serum insulin levels were measured by radioimmunoassay (Alpco Diagnostics, Windham, NH). Glucose measurements were performed at the bedside using a glucose oxidase method as noted above. Serum nonesterified fatty acids were measured using a colorimetric assay (Roche Diagnostics, Indianapolis, IN).

\section{End points}

Fasting and 2-h glucose values and the area under the curve (AUC) for glucose excursion above baseline to 120 and $180 \mathrm{~min}$ (using the trapezoidal rule) were derived from OGTT glucose data as measures of glucose regulation. Measures of $\beta$-cell function included the insulinogenic index ([insulin ${ }_{30 \mathrm{~min}}-$ insulin $\left._{\text {baseline }}\right] /\left[\right.$ glucose $_{30 \mathrm{~min}}-$ glucose $\left._{\text {baseline }}\right]$ ) and the incremental AUC for insulin across the full OGTT. Inverse fasting insulin, HOMA-IR, ${ }^{2}$ the Matsuda Index, ${ }^{6}$ and the QUICKI index of insulin resistance ${ }^{5}$ were calculated and used as representative fasting indices of insulin resistance.

Breath measures of enrichment of exhaled breath for ${ }^{13} \mathrm{CO}_{2}$ were used to calculate change from baseline (e.g., change in 
value at $90 \mathrm{~min}$ [290] = enrichment at $90 \mathrm{~min}$-baseline) and to calculate AUC measures.

The clamp glucose infusion rate-based calculation of glucose disposal rate (GDR) was adjusted for shifts in and out of the glucose space over each 20-min interval, with the average of values from the fourth hour of the clamp procedure taken as the GDR for each individual, as we have previously done. ${ }^{11,18,23}$ Fat-free mass was calculated using the dualenergy x-ray absorptiometry measurements of whole-body fat content, and the GDR per kilogram of fat-free mass $\left(G R_{\text {ffm }}\right)$ was calculated and used in parallel analyses comparing breath testing with clamp measures. ${ }^{24}$ GDR per kilogram of body weight and $\mathrm{GDR}_{\mathrm{ffm}}$ were divided by steadystate insulin concentrations (mean of values from the fourth hour of the procedure) as alternate clamp-derived measures of insulin sensitivity. ${ }^{24}$

\section{Statistical analyses}

Where parameters were not normally distributed, they were transformed to achieve normal distributions if possible in order to apply parametric statistical techniques. Descriptive statistics were compared across groups using one-way analysis of variance. Pearson correlations of the breath test results against the hyperinsulinemic euglycemic clamp measures, and against other surrogate measures of insulin resistance, were obtained. Fisher's $r$-to- $Z$ transform was used to compare regression coefficients using an online calculator at www.vassarstats.net/rdiff.html (accessed December 2012). A calibration analysis was undertaken to evaluate prediction accuracy, and analyses of precision of breath test parameters were undertaken as has been previously described. ${ }^{12}$ In brief, calibration is inverse regression, where the regression equation is used to construct a predictive formula relating each test measure (i.e., breath parameter or traditional surrogate measure of insulin resistance) with the clamp measures. The residuals from the prediction equations were used to calculate the root mean square error (RMSE) of prediction and leaveone-out cross-validation prediction error (CVPE) for each prediction equation. These results were subjected to bootstrapping with 100 repeats in order to construct confidence intervals using a percentile method and to allow statistical

Table 1. Population Descriptors

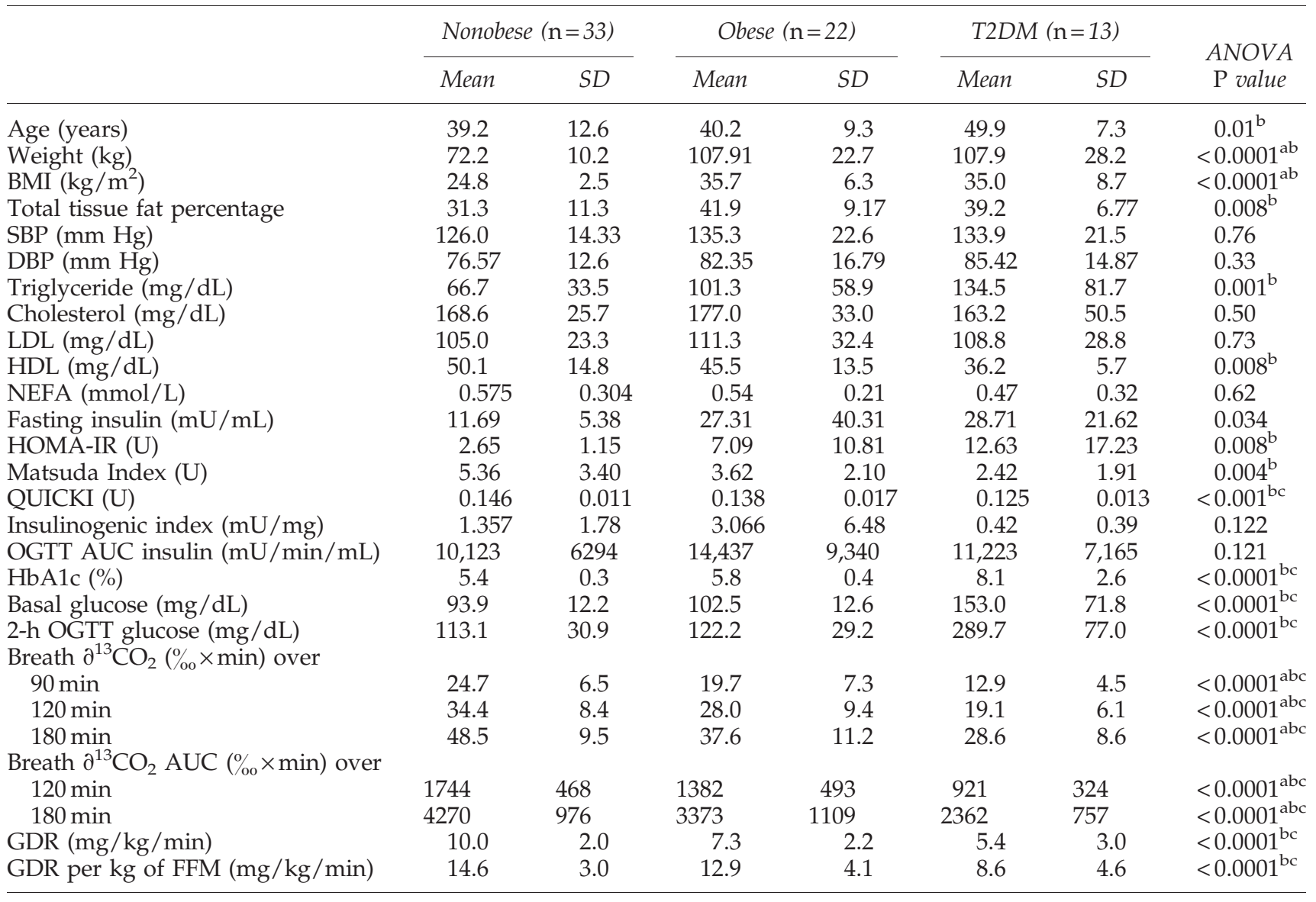

Breath test-derived parameters are presented as delta enrichment comparing a given time point against baseline (e.g., $\partial 90$ indicates change in value from baseline to $90 \mathrm{~min}$ ) or as area under the curve (AUC) from baseline to a given time point (e.g., $\mathrm{AUC}_{120}$, calculated using all data from baseline to $120 \mathrm{~min}$ using the trapezoidal rule).

$P$ values are presented for the one-way analysis of variance (ANOVA) comparing all three groups: ${ }^{\mathrm{a}}$ lean versus obese, ${ }^{\mathrm{b}}$ lean versus type 2 diabetes mellitus (T2DM), and ' obese versus diabetes mellitus.

BMI, body mass index; DBP, diastolic blood pressure; FFM, fat-free mass; GDR, glucose disposal rate; HbA1c, hemoglobin A1c; HDL, highdensity lipoprotein cholesterol; HOMA-IR, homeostasis model assessment of insulin resistance; LDL, low-density lipoprotein cholesterol; NEFA, nonesterified fatty acids; OGTT, oral glucose tolerance test; QUICKI, Quantitative Insulin Sensitivity Check Index; SBP, systolic blood pressure. 
comparison of the precision measures. For the latter, the difference between bootstrapped RMSE or CVPE measures for a given pair of methods was calculated, converted to a binomial distribution, and tested against a normal binomial distribution testing the assumption that differences between mea- sures are distributed around a mean of 0 . These comparisons were performed for all pairwise combinations of parameters within the dataset; for simplicity only the statistical comparisons of breath $\partial^{13} \mathrm{CO}_{2}$ at $180 \mathrm{~min}$ against other measures are presented. Analyses were performed using SPSS version 20

\section{LogHOMA}

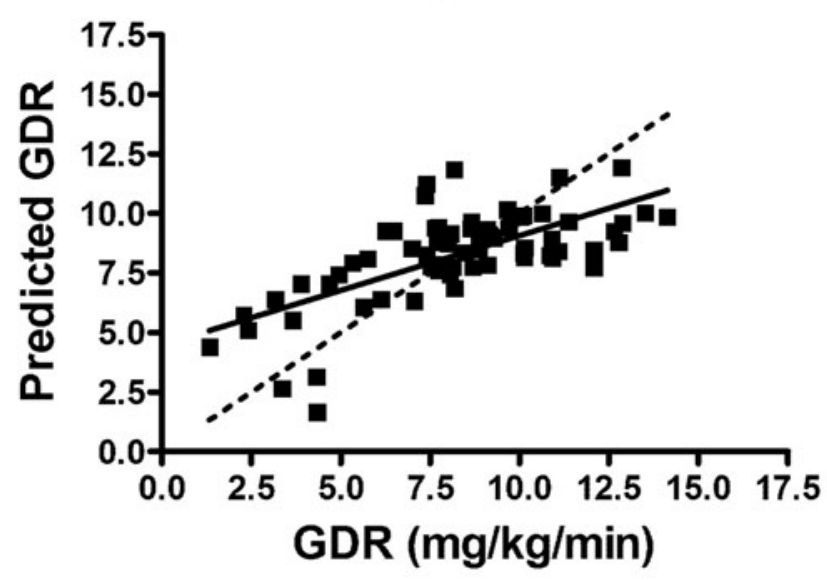

$1 /$ Insulin

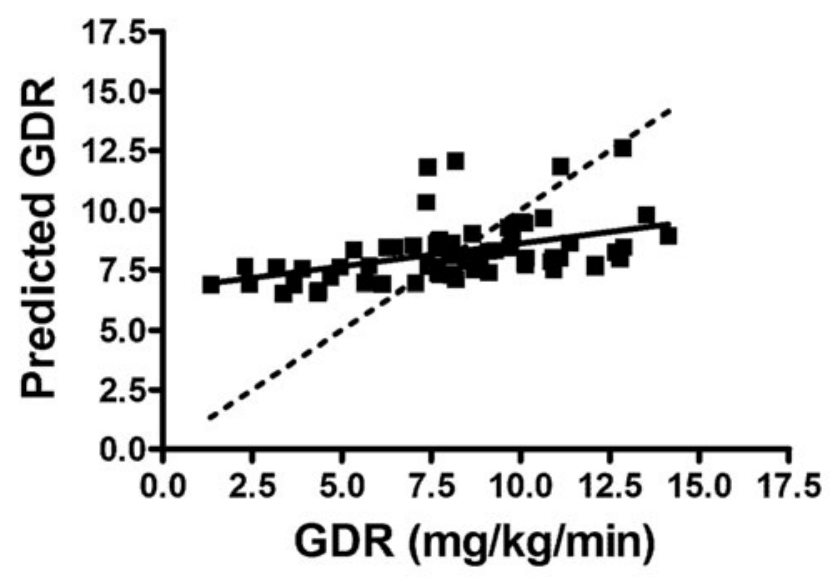

Breath $8180 \mathrm{~min}$

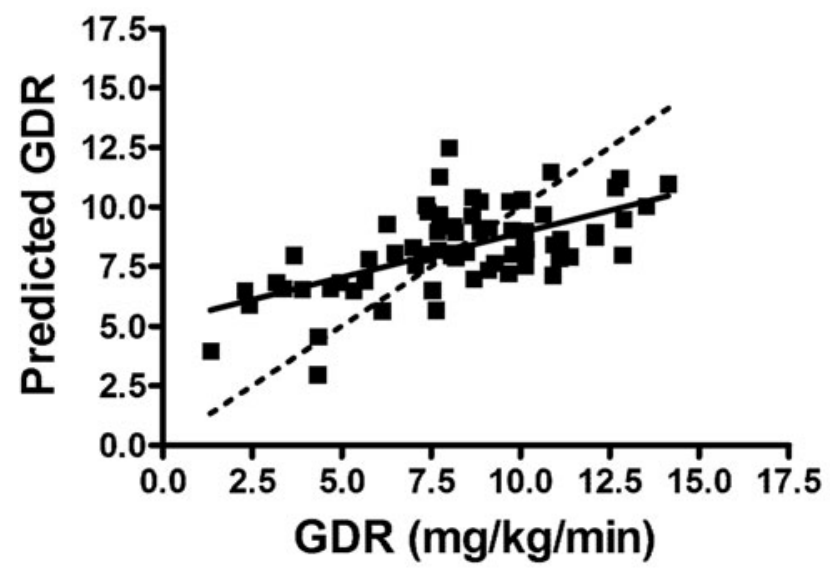

QUICKI

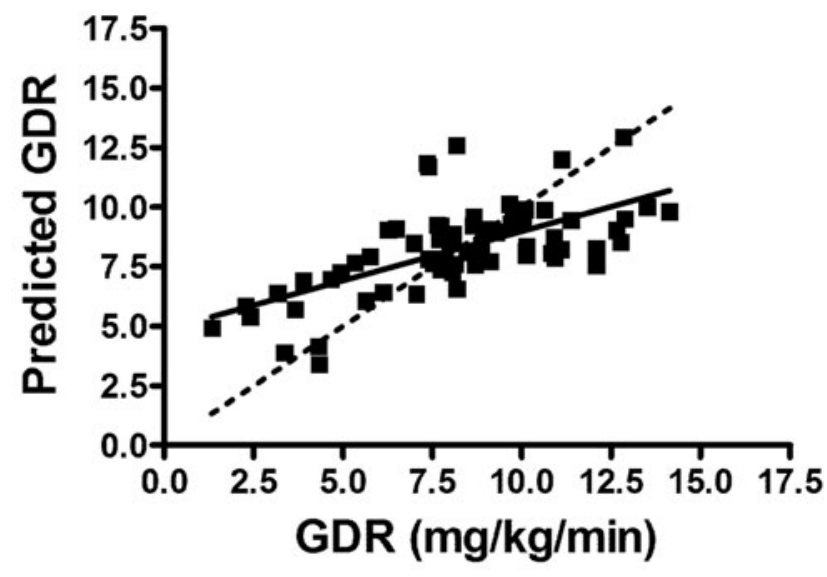

Breath $\delta 90 \mathrm{~min}$

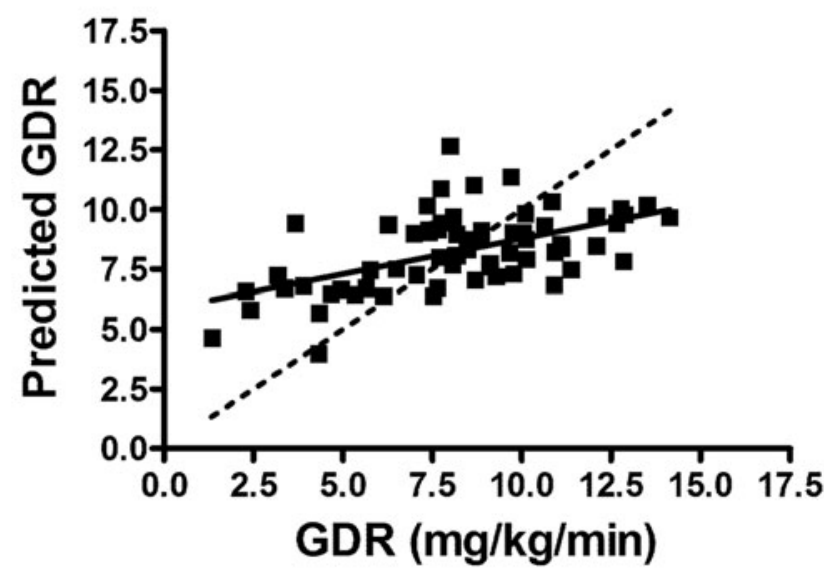

Breath $\delta$ AUC $_{\mathbf{1 8 0 m i n}}$

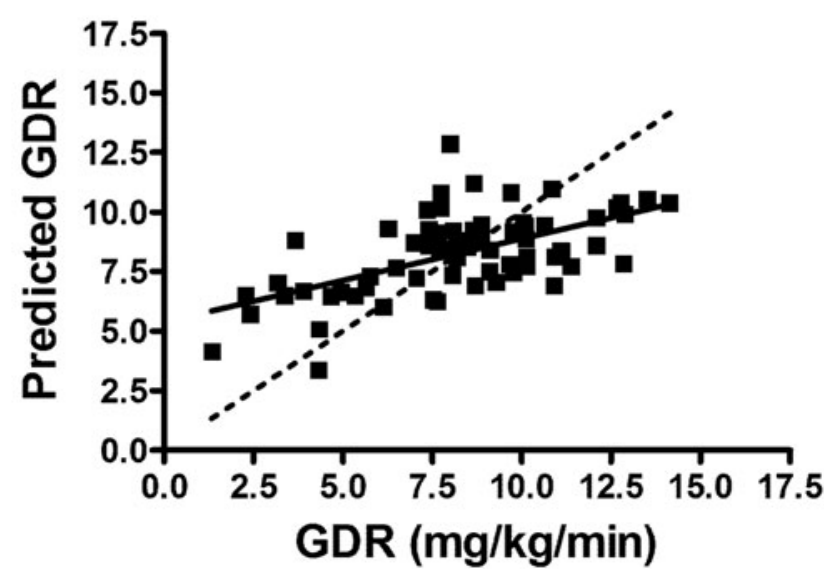

FIG. 1. Calibration analyses for selected breath enrichment and traditional surrogate measures against clamp-derived insulin resistance (glucose disposal rate [GDR]). AUC, area under the curve; HOMA, homeostasis model assessment; QUICKI, Quantitative Insulin Sensitivity Check Index. 
software (IBM, Armonk, NY) or STATA version 12 software (StataCorp, College Station, TX).

\section{Results}

The characteristics of the study participants are described in Table 1. By design, the population was representative of the full spectrum of obesity and glycemic control; data are presented according to usual groupings to provide a full description of our cohort. These groups exhibited expected differences with regard to glucose and insulin-related parameters, including traditional insulin resistance indices derived from fasting insulin and glucose measurements. In the recruited population there was an unintended and statistically significant difference in age across the groups; this did not relate to parameters of breath testing or glucose clamp testing (data not shown). Steady-state insulin concentrations during the hyperinsulinemic clamp procedures did not differ across groups: lean, 1,800.3 $\pm 114.6 \mathrm{pmol} / \mathrm{L}$; obese, 2,010.6 \pm

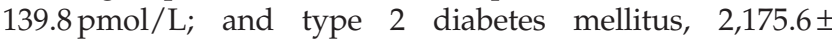
$177.6 \mathrm{pmol} / \mathrm{L}(P=0.19$ by one-way analysis of variance). It is noteworthy that these values were approximately three- to fivefold higher than peak insulin concentrations achieved during the OGTT testing (Table 1).

By including subjects from across the range of glycemia we produced a large observed range of values for breath parameters (e.g., $\partial^{13} \mathrm{CO}_{2}$ AUC180 $=5.0-229.5$, population mean $=120.4 \% \times \min$ ), providing a useful range for comparison against clamp-derived insulin resistance.

As intended, this population exhibited a broad range of insulin resistance (Table 1 and Fig. 1). The correlations of the breath parameters with clamp-derived insulin resistance (GDR by clamp) and with GDR $_{\text {ffm }}$ are presented in Table 2. Single-breath ${ }^{13} \mathrm{CO}_{2}$ enrichment measures from time $=$ +90 min were significantly associated with clamp-derived GDR values, with correlation coefficients of GDR with breath parameters ranging from 0.543 to 0.612 (all $P<0.0001$ ). Similar correlations were seen when comparing clamp measures against the AUC measures for breath parameters $(r=0.548$ and 0.588 for $\mathrm{AUC}_{120}$ and $\mathrm{AUC}_{180}$, respectively). The correlations with single enrichment periods shorter than $90 \mathrm{~min}$ were less robust and are not shown. Parallel results were seen with correlations against $\mathrm{GDR}_{\mathrm{ffm}}$. Correlations of breath parameters against GDR or $\mathrm{GDR}_{\mathrm{ffm}}$ adjusted for steady-state insulin concentrations were similar to the unadjusted parameters, with $r$ values for breath parameters against GDR/ insulin ranging from 0.43 to 0.47 and against $\mathrm{GDR}_{\mathrm{ffm}} /$ insulin ranging from 0.52 to 0.56 (all $P<0.001$ ). Further analyses present only analyses relating to GDR and GDR $\mathrm{ffm}_{\mathrm{fm}}$. Pairwise comparisons of correlations of breath parameters with GDR did not reveal any individual breath-derived measure to be statistically superior to the others. Similarly, the correlations of GDR and $\mathrm{GDR}_{\mathrm{ffm}}$ with breath-derived measures were comparable in magnitude and not statistically different from correlations of GDR with traditional surrogates of insulin resistance. Breath parameters and GDR were not well related within lean subjects only but remained significantly related within the obese and diabetes subgroups (e.g., for breath AUC $_{180}$ versus GDR: lean, $r=0.08, P=0.65$; obese, $r=0.492$, $P=0.02$; and type 2 diabetes mellitus, $r=0.74, P=0.004$ ). Similar results were obtained in subgroup analyses using $\mathrm{GDR}_{\mathrm{ffm}}$ (data not shown).

The results of the calibration analyses of selected breath

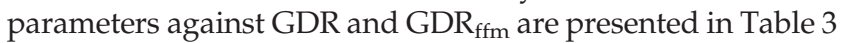
(calibration parameters) and Table 4 (RMSE and CVPE data). The calibration analyses for selected breath parameters against GDR and traditional indices of insulin resistance are presented diagrammatically in Figures 1 and 2 (calibrations and residuals, respectively). Parallel results for evaluations against $\mathrm{GDR}_{\mathrm{ffm}}$ are presented in Figures 3 and 4 . It can be appreciated from Figures 1-4 that the breath-derived predictions are qualitatively comparable to those derived from $\log$ HOMA-IR and QUICKI, whereas the deviation of the prediction slopes with inverse fasting insulin from 1 is greater than those of the other parameters presented. The deviations of the predictions using the Matsuda Index were similar to that of inverse insulin (data not shown) and, as discussed below, this index also exhibited worse measurement precision than other measures.

In Table 4 we present the RMSE and CVPE measures of variability. To keep the presentation focused, we only present comparisons of each measure against the corresponding value for breath $\partial^{13} \mathrm{CO}_{2}$ at $180 \mathrm{~min}$. Within a given set of calibrations, a lower value for RMSE or CVPE indicates higher precision of the prediction. Breath $\partial^{13} \mathrm{CO}_{2}$ at $180 \mathrm{~min}$ RMSE and CVPE values for predictions of GDR and $\mathrm{GDR}_{\mathrm{ffm}}$ were not

Table 2. Correlations of Breath Test Parameters with Insulin Resistance Measures

\begin{tabular}{|c|c|c|c|c|c|}
\hline & 1/Insulin & $\log H O M A-I R$ & Matsuda Index & $G D R$ & $G D R_{f f m}$ \\
\hline 1/Insulin & & & & $+0.439(<0.0001)$ & $0.295(<0.016)$ \\
\hline logHOMA-IR & & & & $-0.678(<0.0001)$ & $-0.580(<0.0001)$ \\
\hline Matsuda Index & & & & $0.556(<0.0001)$ & $0.340(0.005)$ \\
\hline QUICKI & & & & $0.643(<0.001)$ & $0.524(<0.0001)$ \\
\hline \multicolumn{6}{|c|}{$\partial^{13} \mathrm{CO}_{2}(\% \times$ min $)$ over } \\
\hline $90 \mathrm{~min}$ & $+0.361(0.002)$ & $-0.574(<0.0001)$ & $+0.304(0.012)$ & $+0.543(<0.0001)$ & $0.578(<0.0001)$ \\
\hline $120 \mathrm{~min}$ & $+0.351(0.003)$ & $-0.585(<0.0001)$ & $+0.293(0.015)$ & $+0.580(<0.0001)$ & $0.580(<0.0001)$ \\
\hline $180 \mathrm{~min}$ & $+0.334(0.005)$ & $-0.596(<0.0001)$ & $+0.292(0.016)$ & $+0.612(<0.0001)$ & $0.661(<0.0001)$ \\
\hline \multicolumn{6}{|c|}{$\partial^{13} \mathrm{CO}_{2}$ AUC $(\% \times \min )$ over } \\
\hline $120 \mathrm{~min}$ & $+0.334(0.005)$ & $-0.557(<0.0001)$ & $+0.275(0.023)$ & $+0.556(<0.0001)$ & $0.548(<0.0001)$ \\
\hline $180 \mathrm{~min}$ & $+0.348(0.004)$ & $-0.592(<0.0001)$ & $+0.293(0.015)$ & $+0.592(<0.0001)$ & $0.628(<0.0001)$ \\
\hline
\end{tabular}

Values for Pearson correlations are presented as $r$ value ( $P$ value). Breath measures (per-mille enrichment above baseline) are calculated

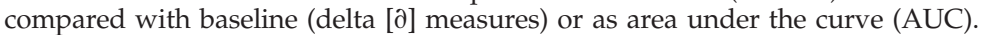

GDR, glucose disposal rate; HOMA-IR, homeostasis model assessment of insulin resistance; QUICKI, Quantitative Insulin Sensitivity Check Index. 
Table 3. Calibration Analysis Parameters for Predictions of Glucose Disposal Rate or Glucose Disposal Rate per Kilogram of Fat-Free Mass from Breath MEASUREMENTS AND FROM TRAditional INDICES of INSULIN RESISTANCE

\begin{tabular}{|c|c|c|c|c|}
\hline & \multicolumn{4}{|c|}{ Predicting } \\
\hline & \multicolumn{2}{|c|}{$G D R$} & \multicolumn{2}{|c|}{$G D R_{f f m}$} \\
\hline & Intercept & Slope & Intercept & Slope \\
\hline 1/Insulin & 6.42 & 20.43 & 11.10 & 20.04 \\
\hline logHOMA-IR & 11.13 & -2.25 & 16.48 & -2.80 \\
\hline Matsuda Index & 6.00 & 0.538 & 10.88 & 0.479 \\
\hline QUICKI & -8.20 & 118.3 & -6.66 & 140.6 \\
\hline Breath 290 & 4.03 & 0.202 & 6.33 & 0.314 \\
\hline Breath $\partial 120$ & 3.35 & 0.167 & 5.31 & 0.258 \\
\hline Breath $\partial 180$ & 2.41 & 0.142 & 3.70 & 0.222 \\
\hline Breath $\mathrm{AUC}_{120}$ & 3.92 & $2.94 \times 10^{-3}$ & 6.27 & $4.50 \times 10^{-3}$ \\
\hline Breath $\mathrm{AUC}_{180}$ & 3.15 & $1.41 \times 10^{-3}$ & 4.99 & $2.18 \times 10^{-3}$ \\
\hline
\end{tabular}

$\partial$, change in value from baseline; AUC, area under the curve; GDR, glucose disposal rate; $\mathrm{GDR}_{\mathrm{ffm}}$, glucose disposal rate per kilogram of fat-free mass; HOMA-IR, homeostasis model assessment of insulin resistance; QUICKI, Quantitative Insulin Sensitivity Check Index.

statistically different from breath $\mathrm{AUC}_{180}$ values. Breath $\partial^{13} \mathrm{CO}_{2}$ at $180 \mathrm{~min}$ was significantly more precise than other breath-derived parameters. Breath ${ }^{13} \mathrm{CO}_{2}$ at $180 \mathrm{~min}$ was more precise than inverse insulin and the Matsuda Index but was less precise than either logHOMA-IR or the QUICKI index of insulin resistance. The absolute values of RMSE and CVPE were higher for the predictions of $\mathrm{GDR}_{\mathrm{ffm}}$; this simply reflects the higher absolute values of $\mathrm{GDR}_{\mathrm{ffm}}$ compared with GDR and does not imply that predictions of $\mathrm{GDR}_{\mathrm{ffm}}$ are less precise than those of GDR.

\section{Discussion}

We have demonstrated that the ${ }^{13} \mathrm{C}$-labeled OGTT breath test is a valid surrogate of clamp-derived insulin resistance measurements, with good prediction accuracy and precision. Breath-derived measures were strongly correlated with the gold standard measurement of insulin sensitivity. The relationship was robust using many parameters derived from the breath testing, with the strongest correlations observed between clamp-derived GDR and the single measurement of breath enrichment taken at $180 \mathrm{~min}$ after ingestion $(r=0.612, P<0.0001)$ and between the GDR and breath AUC for the $3 \mathrm{~h}$ of observation $(r=0.588, P<0.0001)$. Comparably robust relationships were evident with earlier time points, with strong and significant correlations observed with measures from $90 \mathrm{~min}$ after ingestion $(r=0.543$, $P<0.001)$. Similar patterns were seen for correlations of breath parameters with $\mathrm{GDR}_{\mathrm{ffm}}$ and with GDR/insulin and $\mathrm{GDR}_{\mathrm{ffm}} /$ insulin.

In calibration analyses, modest differences in precision among the predictions of GDR and GDR $\mathrm{ffm}_{\mathrm{fm}}$ favored the breath $\partial^{13} \mathrm{CO}_{2}$ at $180 \mathrm{~min}$ and breath $\mathrm{AUC}_{180}$ measures. These parameters were superior in their prediction accuracy than the inverse fasting insulin and Matsuda Index, two commonly used indices of insulin resistance, but were statistically inferior to the logHOMA-IR and QUICKI indices.

As is evident in Figures 1 and 3, the observed linear relationship between each breath test result and the formal measure of insulin resistance produced no natural threshold to distinguish groups of individuals with differing insulin sensitivity. This reflects the continuous distribution of insulin sensitivity that is observed in populations and is what is typically observed with other measures of insulin sensitivity, including the clamp data presented here. ${ }^{9,10}$

A small set of prior studies has reported that surrogate measures of insulin sensitivity are correlated with exhaled breath $\mathrm{CO}_{2}$ measures following a labeled oral glucose load. A similar breath test base on exhaled $\mathrm{CO}_{2}$ following glucose ingestion correlated significantly with HOMA-IR $(r=-0.40$, $P<0.0001)$ in Asian Indians without diabetes. ${ }^{25}$ Similarly, associations between $\left[{ }^{13} \mathrm{C}\right]$ glucose breath test and indices of insulin resistance including HOMA-IR and QUICKI were found in a cohort of obese youth with type 2 diabetes mellitus

Table 4. Precision Estimates and Comparisons Between Selected Breath Parameters and Other Surrogates in the Prediction of Clamp-Derived Glucose Disposal Rates

\begin{tabular}{|c|c|c|c|c|}
\hline & \multicolumn{4}{|c|}{ Predicting } \\
\hline & \multicolumn{2}{|c|}{$G D R$} & \multicolumn{2}{|c|}{$G D R_{f f m}$} \\
\hline & RMSE & CVPE & RMSE & CVPE \\
\hline 1/Insulin & $2.63(2.18-2.95)^{\mathrm{C}}$ & $2.68(2.63-3.05)^{c}$ & $4.11(3.34-4.63)^{\mathrm{c}}$ & $4.20(3.52-4.86)^{\mathrm{C}}$ \\
\hline LogHOMA-IR & $2.15(1.82-2.41)^{\mathrm{c}}$ & $2.21(1.90-2.49)^{\mathrm{c}}$ & $3.51(2.89-3.94)^{c}$ & $3.57(3.05-4.12)^{\mathrm{C}}$ \\
\hline Matsuda Index & $2.44(2.02-2.74)^{\mathrm{c}}$ & $2.51(2.09-2.89)^{\mathrm{c}}$ & $4.05(3.29-4.53)^{c}$ & $4.14(3.52-4.81)^{\mathrm{C}}$ \\
\hline QUICKI & $2.24(1.88-2.56)^{\mathrm{c}}$ & $2.29(1.93-2.62)^{\mathrm{c}}$ & $3.66(3.02-4.13)^{c}$ & $3.74(3.10-4.32)^{\mathrm{C}}$ \\
\hline Breath 290 & $2.46(2.02-2.75)^{\mathrm{c}}$ & $2.51(2.18-2.86)^{\mathrm{c}}$ & $3.51(2.88-4.10)^{\mathrm{c}}$ & $3.57(2.91-4.17)^{\mathrm{C}}$ \\
\hline Breath 2120 & $2.39(2.04-2.71)^{\mathrm{a}}$ & $2.44(2.08-2.75)$ & $3.39(2.67-3.93)^{c}$ & $3.45(2.82-3.99)$ \\
\hline Breath $\mathrm{AUC}_{120}$ & $2.44(2.04-2.78)^{\mathrm{b}}$ & $2.49(2.15-2.87)^{b}$ & $3.50(2.83-4.08)^{b}$ & $3.56(2.94-3.14)^{\mathrm{C}}$ \\
\hline Breath $\mathrm{AUC}_{180}$ & $2.36(2.01-2.65)$ & $2.41(2.08-2.75)$ & $3.34(2.72-3.88)$ & $3.40(2.82-3.94)$ \\
\hline Breath $\partial 180$ & $2.32(1.98-2.57)$ & $2.35(2.05-2.65)$ & $3.23(2.63-3.67)$ & $3.29(2.73-3.76)$ \\
\hline
\end{tabular}

Comparisons between pairs of measures are performed within each column only (e.g., comparing root mean square error [RMSE] for

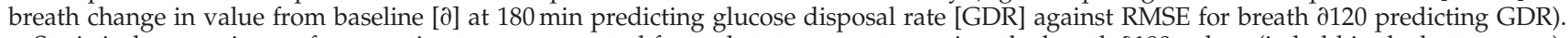

Statistical comparisons of error estimates are presented for each test parameter against the breath 2180 values (in bold in the bottom row):

${ }^{\mathrm{a}} P<10^{-3},{ }^{\mathrm{b}} \mathrm{P}<10^{-4},{ }^{\mathrm{c}} \mathrm{P}<10^{-5}$. Values without a symbol are not different statistically from the breath $\partial 180$ value.

CVPE, cross-validation prediction error; $\mathrm{GDR}_{\mathrm{ffm}}$, glucose disposal rate per kilogram of fat-free mass. 


\section{LogHOMA}

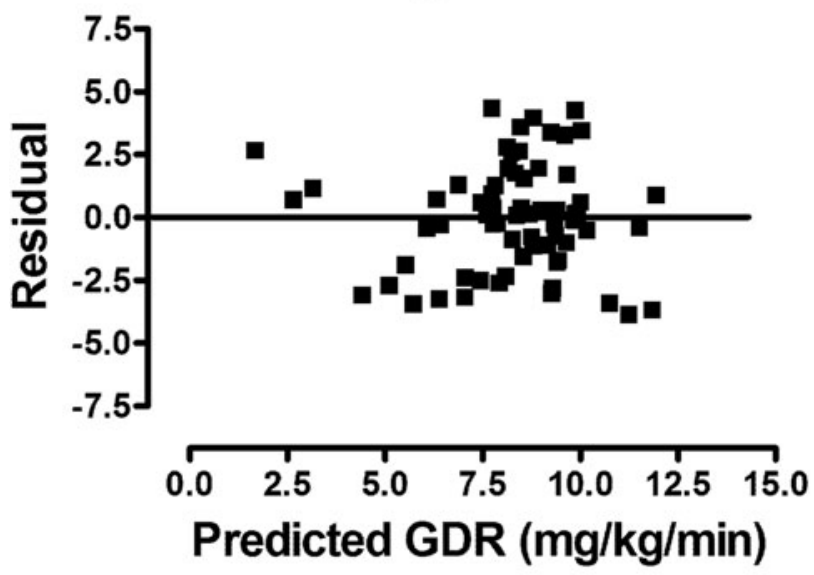

1/Insulin

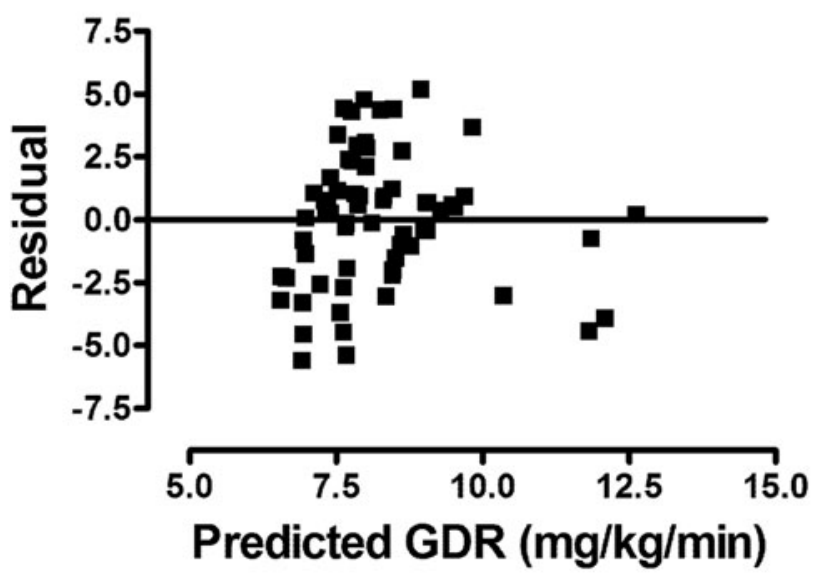

Breath $8180 \mathrm{~min}$

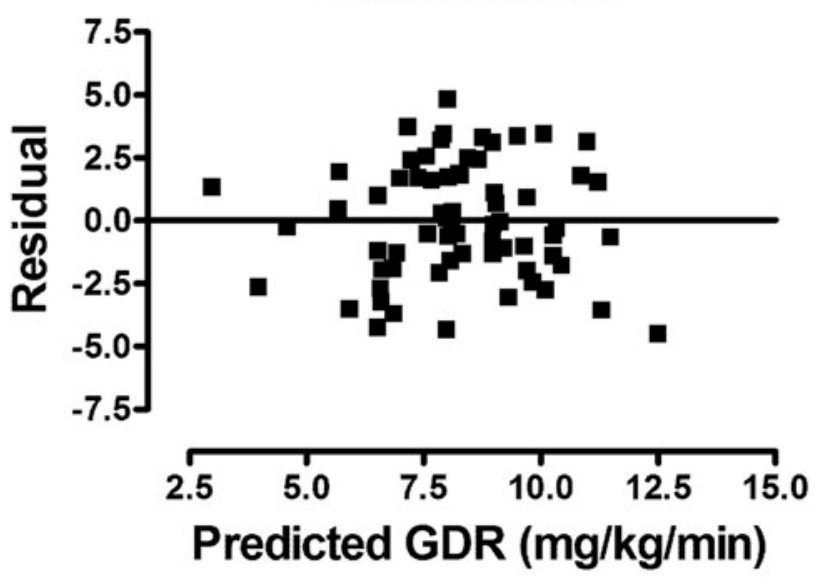

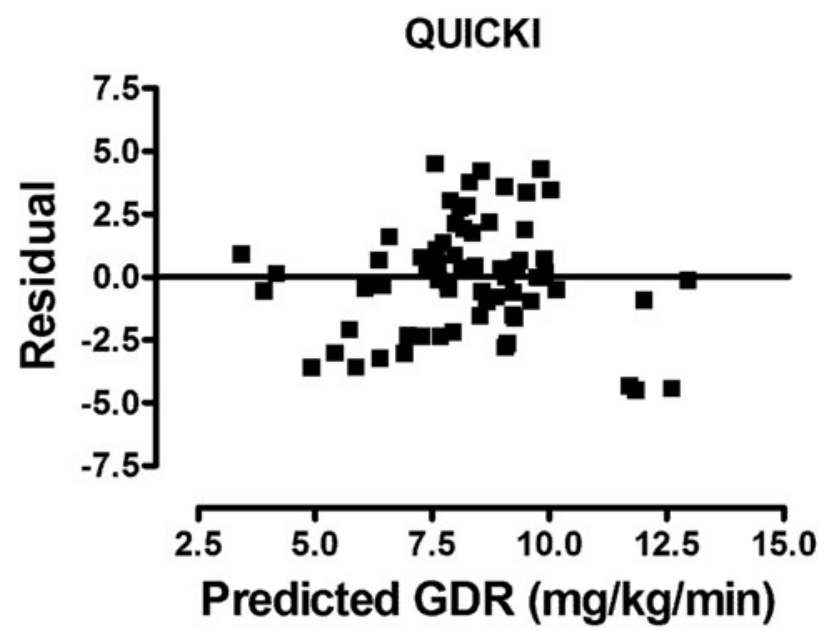

Breath $\delta 90 \mathrm{~min}$

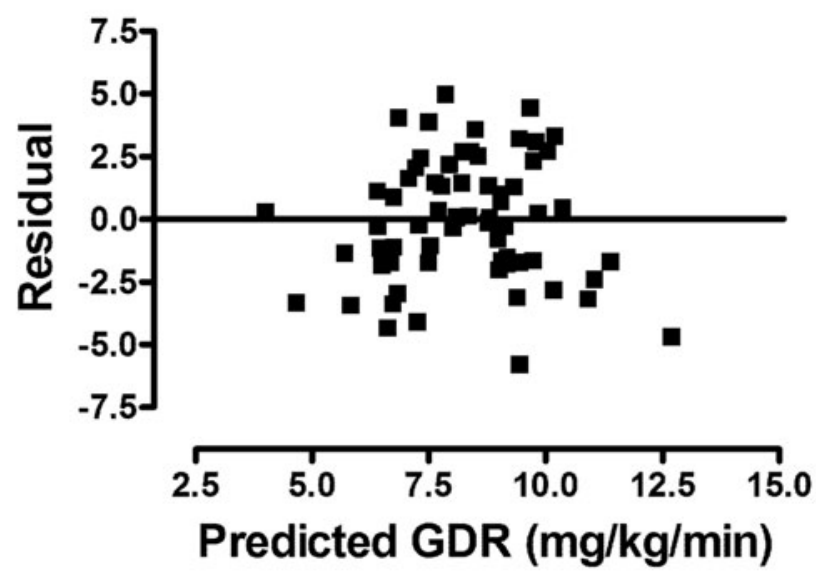

Breath $\mathrm{AUC}_{180 \mathrm{~min}}$

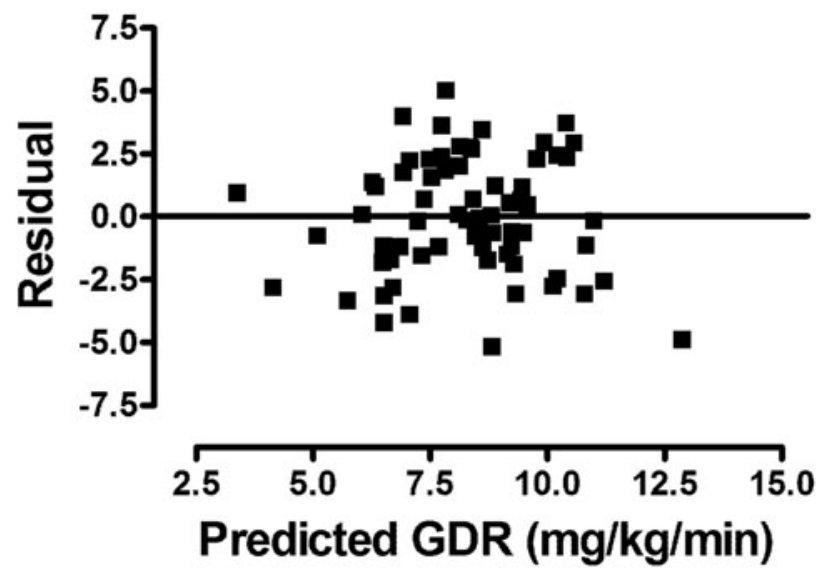

FIG. 2. Residual plots for calibrations against glucose disposal rate (GDR). AUC, area under the curve; HOMA, homeostasis model assessment; QUICKI, Quantitative Insulin Sensitivity Check Index.

$(r=-0.5, P<0.01) .{ }^{15}$ A comparable magnitude of correlation $(r=-0.4, P=0.001)$ was observed in a cohort of adult Mexican participants without diabetes, using a 90 -min breath parameter ${ }^{26}$ And, finally, in a small sample of subjects without diabetes studied before and after aerobic exercise, the 90-min breath enrichment measured before exercise was strongly correlated with various indices of insulin resistance, including HOMA-IR $(r=-0.48, P=0.03) .{ }^{14}$

Only one prior study ${ }^{17}$ performed direct comparisons of breath testing against the gold standard euglycemic hyperinsulinemic clamp as we have done in the current project. Similar to our observations, in that study the breath test was 


\section{LogHOMA}

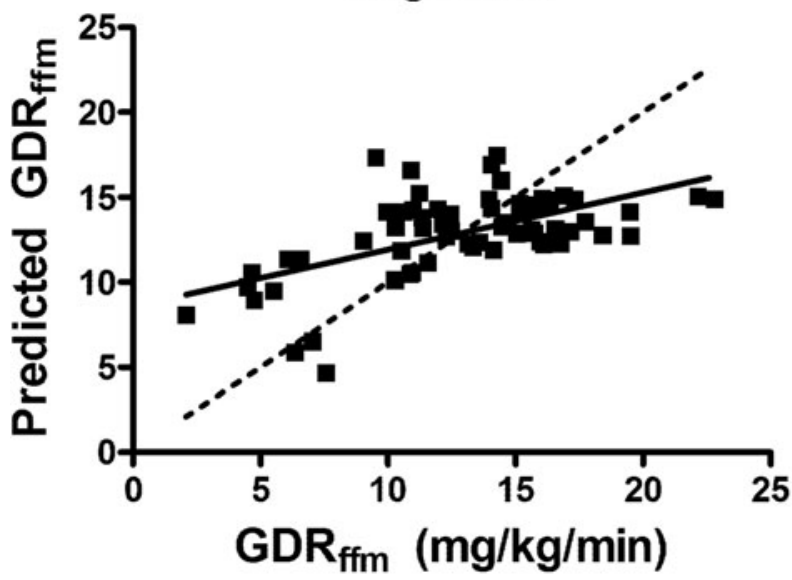

$1 /$ Insulin

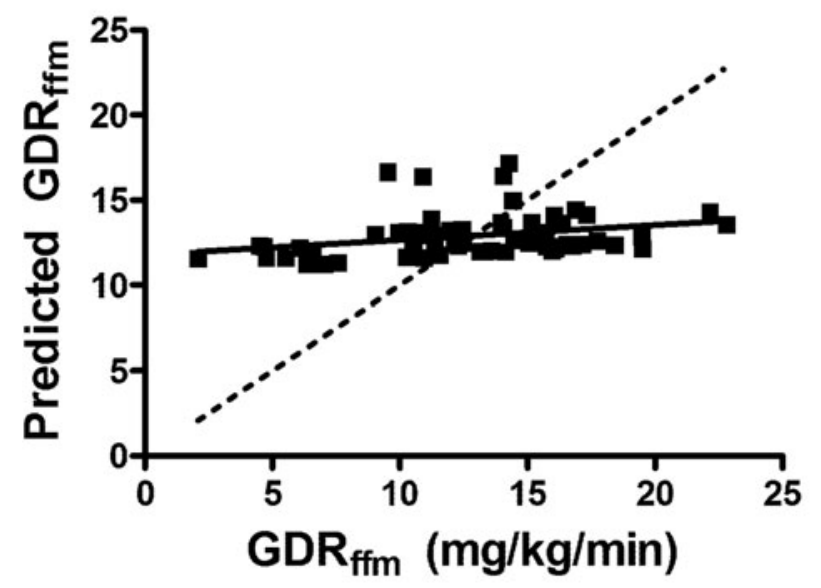

Breath $8180 \mathrm{~min}$

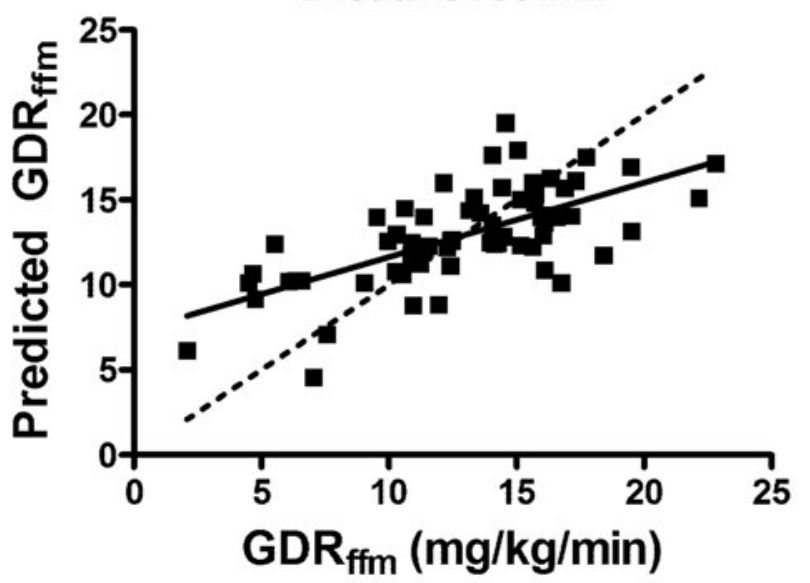

\section{QUICKI}

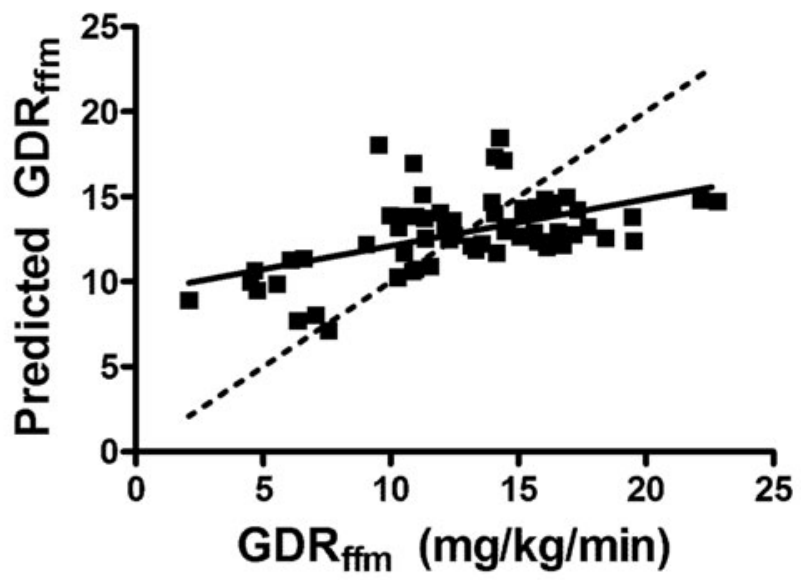

Breath $\delta 90 \mathrm{~min}$

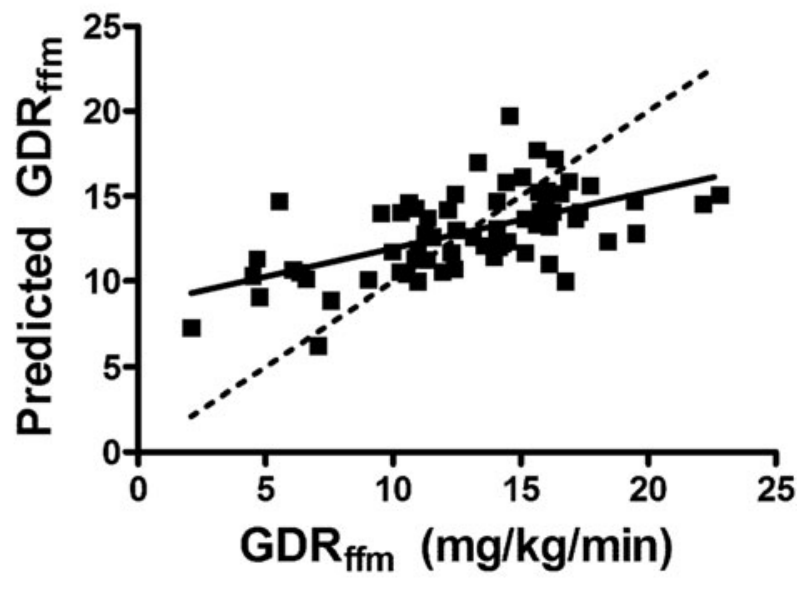

Breath $\mathrm{AUC}_{180 \mathrm{~min}}$

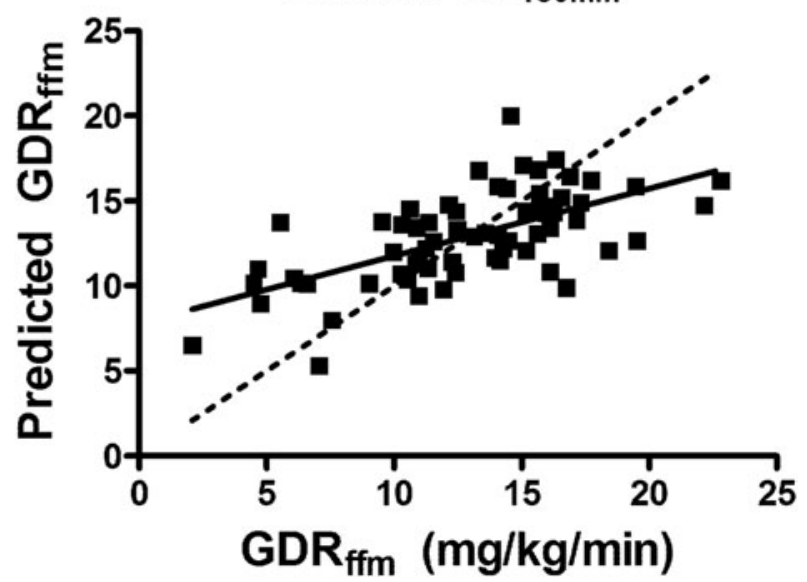

FIG. 3. Calibration analyses for selected breath enrichment and traditional surrogate measures against clamp-derived insulin resistance (glucose disposal rate) per kilogram of fat-free mass $\left(\mathrm{GDR}_{\mathrm{ffm}}\right)$. AUC, area under the curve; HOMA, homeostasis model assessment; QUICKI, Quantitative Insulin Sensitivity Check Index.

strongly correlated with clamp-derived measures of insulin sensitivity $(r=0.7) .{ }^{17}$ In the current report our population was larger and more representative of the full spectrum of obesity, glycemic status, and insulin sensitivity, and we have considerably extended the analyses of these relationships by exploring prediction accuracy and precision and compared these parameters against commonly used surrogate measures of insulin resistance.

A similar analytic approach has been used to demonstrate superiority in accuracy and precision of QUICKI and 

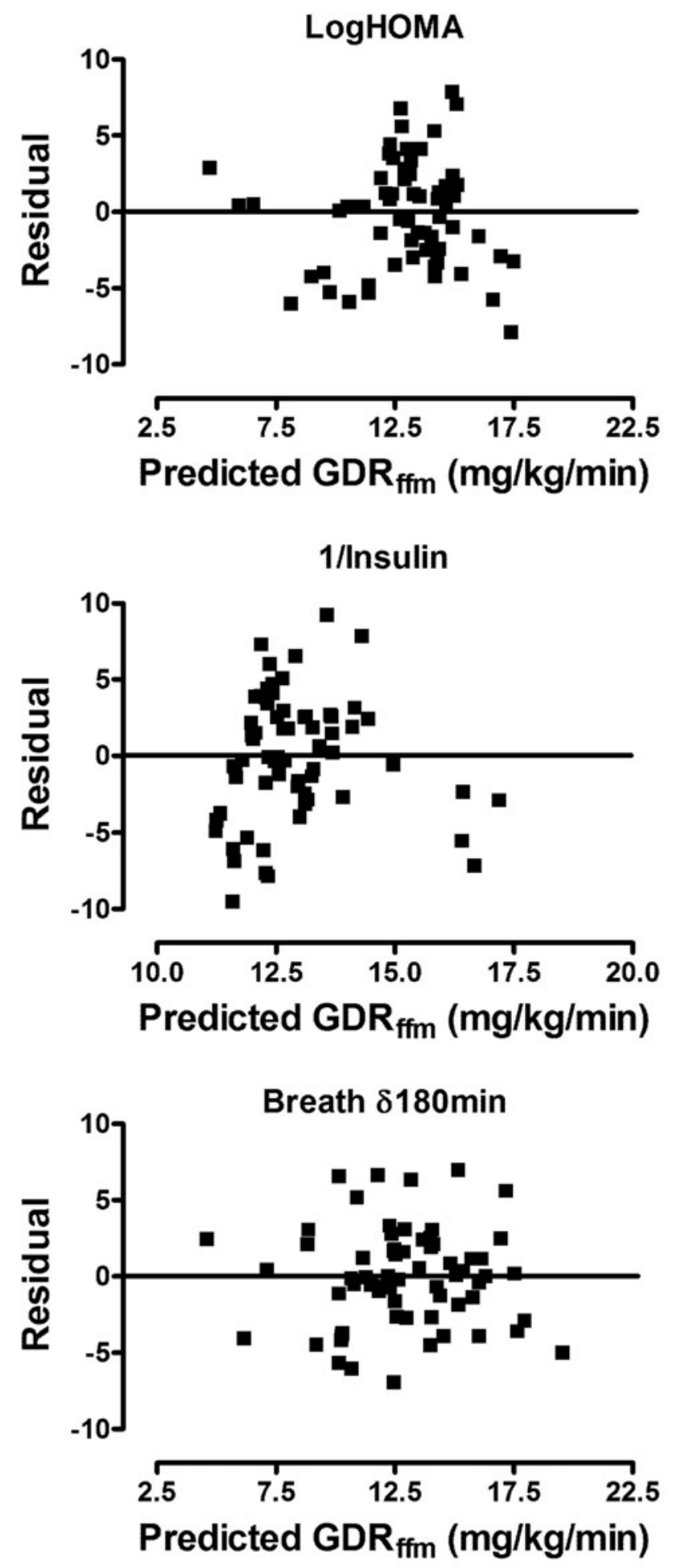
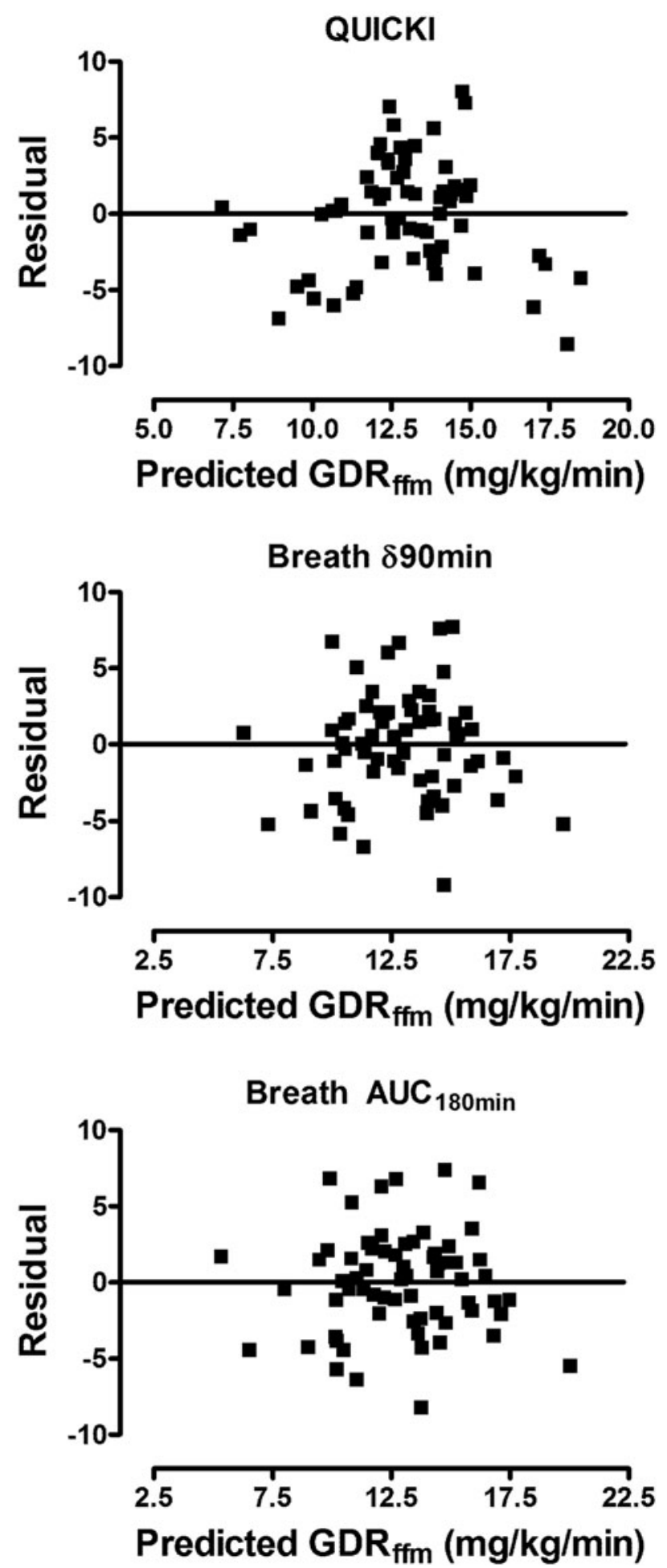

FIG. 4. Residual plots for calibrations against glucose disposal rate per kilogram of fat-free mass (GDR $\mathrm{ffm})$. AUC, area under the curve; HOMA, homeostasis model assessment; QUICKI, Quantitative Insulin Sensitivity Check Index.

$\log$ HOMA to other surrogate indices of insulin resistance. ${ }^{12}$ Our results were parallel, with these surrogates proving superior to other insulin and glucose-derived measures of insulin resistance, including the Matsuda Index (parameters in Table 4; statistical comparisons not shown). Breath $\partial^{13} \mathrm{CO}_{2}$ at 180 min was superior to inverse insulin and the Matsuda Index but inferior to logHOMA-IR and QUICKI in prediction precision. The overall values are quite comparable, however, and the advantages of breath testing versus blood sampling will help determine which surrogate is preferred in a given application.

It is evident from Tables 1 and 2 that the apparent correlation with GDR improves with greater time following the glucose ingestion, with greater separation of glycemia groups 
with greater duration of sampling. Furthermore, the precision of the prediction of GDR from breath parameters in calibration analyses improves with longer duration of sampling (Table 4). Our observations stopped at $3 \mathrm{~h}$ after ingestion as this seemed a practical limit to the routine application of this test. However, the analyses of prediction accuracy provided evidence for statistical superiority of breath $\partial^{13} \mathrm{CO}_{2}$ at $180 \mathrm{~min}$ and breath $\mathrm{AUC}_{180}$ compared with indices derived using earlier time points. In prior reports we have found that the 180-min enrichment measurement relates best to glucose parameters. ${ }^{13,16}$ The particular breath end point that is optimal for a given application will depend on the planned use of the breath data, but in general the 180 -min time point appears to be advantageous.

Overall, the breath measure can be viewed as a useful surrogate measure of insulin sensitivity with correlations comparable to but not superior to those of the traditional fasting indices and with prediction accuracy superior to inverse insulin and the Matsuda Index but inferior to $\operatorname{logHOMA-IR}$ and QUICKI. However, the breath test has advantages relating to noninvasive testing methodology, ease of performance, and informative differences relating to the physiologic underpinnings of the measurement. The potential applications of this test include physiologic studies where the breath test's dependence on rates of tissue metabolism is useful and clinical circumstances where the ease of testing or noninvasive sampling method provide advantages. Examples of the latter include glucose tolerance testing in pediatric populations and in the setting of screening for gestational diabetes mellitus. Further testing is planned to move forward in each of these areas.

\section{Limitations}

In the current study we have not evaluated participants with pulmonary disease or history of smoke exposure, where pulmonary gas diffusion patterns may be altered and affect breath gas composition. We did not populate each subgroup equally, as we were recruiting participants to represent the spectrum of glycemia without intending to make evaluations within each subgroup or comparisons across subgroups. Therefore the current dataset is not powered for these sorts of analyses. We elected to use the most precise method for ${ }^{13} \mathrm{CO}_{2}$ assessment using mass spectrometry for the current testing, but widespread use would likely involve a less expensive infrared spectroscopy method, which was not evaluated. In other applications, the correlation of ${ }^{13} \mathrm{CO}_{2} /{ }^{12} \mathrm{CO}_{2}$ measured by infrared and mass spectrometry ranges from 0.80 to 0.97 following an oral load of an analogous tracer. ${ }^{27,28}$ Future studies will need to evaluate the direct target populations where the noninvasive nature of this test carries the largest advantages, namely, pediatric and pregnant women. And, the utility of this test as a measure of integrated metabolism needs further exploration and development before it can be broadly applied in this manner.

\section{Conclusions}

We have shown that a simple, breath test-based test of breath ${ }^{13} \mathrm{CO}_{2}$ enrichment following ingestion of $\left[{ }^{13} \mathrm{C}\right]$ glucose in the context of a standard 75-g OGTT can provide a surrogate measure of insulin resistance comparable to other widely applied surrogate measures (Tables 2 and 4). The principal strengths of this method are the noninvasive nature of sampling, the simplicity of obtaining the required measurements, and the conceptual advantage that the measured result reflects integrated fuel metabolism after the glucose load. Also, the breath method can provide a direct measure of glycemic response in addition to serving as a surrogate of insulin resistance. Disadvantages of the method include the need for a physical measurement of the breath sample (by mass spectrometry or infrared spectroscopy), the lack of standardization to date, and the limited populations where the noninvasive nature of the breath test overcomes the advantages of previously established methods for assessment of glycemia or insulin resistance.

\section{Acknowledgments}

This project was supported by grant 2R44DK072637 from the National Institute of Diabetes and Digestive and Kidney Diseases and by the Indiana Clinical and Translational Sciences Institute funded in part by grant TR000006 (Clinical Research Center support) from the National Center for Advancing Translational Sciences, Clinical and Translational Sciences Award, National Institutes of Health. We gratefully acknowledge the contributions of study staff and Clinical Research Center support staff and the willing participation of our study volunteers.

\section{Author Disclosure Statement}

M.J. and S.S. are employees of BioChem Analysis Inc., and M.J. is also an employee of the Center for Stable Isotope Research, Inc. These entities are developing medical tests based on stable isotopes, including the breath test presented here. The project was funded by a National Institutes of Health Small Business Innovation Research grant to BioChem Analysis Inc. No competing financial interests exist for M.H., R.V.C., R.L.C., and K.J.M. The data collection, analysis, and presentation were performed independent of the commercial sponsor.

\section{References}

1. DeFronzo RA, Tobin JD, Andres R: Glucose clamp technique: a method for quantifying insulin secretion and resistance. Am J Physiol 1979;237:E214-E223.

2. Matthews DR, Hosker JP, Rudenski AS, Naylor BA, Treacher DF, Turner RC: Homeostasis model assessment: insulin resistance and beta-cell function from fasting plasma glucose and insulin concentrations in man. Diabetologia 1985;28: 412-419.

3. Wallace TM, Levy JC, Matthews DR: Use and abuse of HOMA modeling. Diabetes Care 2004;27:1487-1495.

4. Levy JC, Matthews DR, Hermans MP: Correct homeostasis model assessment (HOMA) evaluation uses the computer program. Diabetes Care 1998;21:2191-2192.

5. Katz A, Nambi SS, Mather K, Baron AD, Follmann DA, Sullivan G, Quon MJ: Quantitative Insulin Sensitivity Check Index: a simple, accurate method for assessing insulin sensitivity in humans. J Clin Endocrinol Metab 2000;85:2402-2410.

6. Matsuda M, DeFronzo RA: Insulin sensitivity indices obtained from oral glucose tolerance testing: comparison with the euglycemic insulin clamp. Diabetes Care 1999;22:1462-1470.

7. Muniyappa R, Lee S, Chen H, Quon MJ: Current approaches for assessing insulin sensitivity and resistance in vivo: ad- 
vantages, limitations, and appropriate usage. Am J Physiol Endocrinol Metab 2008;294:E15-E26.

8. Sarafidis PA, Lasaridis AN, Nilsson PM, Pikilidou MI, Stafilas PC, Kanaki A, Kazakos K, Yovos J, Bakris GL: Validity and reproducibility of HOMA-IR, 1/HOMA-IR, QUICKI and McAuley's indices in patients with hypertension and type II diabetes. J Hum Hypertens 2007;21:709-716.

9. Tam CS, Xie W, Johnson WD, Cefalu WT, Redman LM, Ravussin E: Defining insulin resistance from hyperinsulinemiceuglycemic clamps. Diabetes Care 2012;35:1605-1610.

10. Bonora E, Targher G, Alberiche M, Formentini G, Calcaterra F, Lombardi S, Marini F, Poli M, Zenari L, Raffaelli A, Perbellini S, Zenere MB, Saggiani F, Bonadonna RC, Muggeo M: Predictors of insulin sensitivity in Type 2 diabetes mellitus. Diabet Med 2002;19:535-542.

11. Mather KJ, Hunt AE, Steinberg HO, Paradisi G, Hook G, Katz A, Quon MJ, Baron AD: Repeatability characteristics of simple indices of insulin resistance: implications for research applications. J Clin Endocrinol Metab 2001;86:54575464.

12. Chen H, Sullivan G, Quon MJ: Assessing the predictive accuracy of QUICKI as a surrogate index for insulin sensitivity using a calibration model. Diabetes 2005;54:19141925.

13. Singal $P$, Janghorbani M, Schuette SA, Chisholm R, Mather $\mathrm{KJ}$ : Intra-individual variability of $\mathrm{CO}_{2}$ breath isotope enrichment compared to blood glucose in the oral glucose tolerance test. Diabetes Technol Ther 2010;12:947-953.

14. Mizrahi M, Lalazar G, Adar T, Raz I, Ilan Y: Assessment of insulin resistance by a ${ }^{13} \mathrm{C}$ glucose breath test: a new tool for early diagnosis and follow-up of high-risk patients. Nutr J 2010;9:25.

15. Jetha MM, Nzekwu U, Lewanczuk RZ, Ball GD: A novel, non-invasive ${ }^{13} \mathrm{C}$-glucose breath test to estimate insulin resistance in obese prepubertal children. J Pediatr Endocrinol Metab 2009;22:1051-1059.

16. Dillon EL, Janghorbani M, Angel JA, Casperson SL, Grady JJ, Urban RJ, Volpi E, Sheffield-Moore M: Novel noninvasive breath test method for screening individuals at risk for diabetes. Diabetes Care 2009;32:430-435.

17. Lewanczuk RZ, Paty BW, Toth EL: Comparison of the $\left[{ }^{13} \mathrm{C}\right]$ glucose breath test to the hyperinsulinemic-euglycemic clamp when determining insulin resistance. Diabetes Care 2004;27:441-447.

18. Lteif A, Vaishnava P, Baron AD, Mather KJ: Endothelin limits insulin action in obese/insulin-resistant humans. Diabetes 2007;56:728-734.
19. Lteif AA, Fulford AD, Considine RV, Gelfand I, Baron AD, Mather KJ: Hyperinsulinemia fails to augment ET-1 action in the skeletal muscle vascular bed in vivo in humans. Am J Physiol Endocrinol Metab 2008;295:E1510-E1517.

20. O'Shaughnessy IM, Myers TJ, Stepniakowski K, Nazzaro P, Kelly TM, Hoffmann RG, Egan BM, Kissebah AH: Glucose metabolism in abdominally obese hypertensive and normotensive subjects. Hypertension 1995;26:186-192.

21. Paquot N, Scheen AJ, Dirlewanger M, Lefebvre PJ, Tappy L: Hepatic insulin resistance in obese non-diabetic subjects and in type 2 diabetic patients. Obes Res 2002;10:129-134.

22. Staehr P, Hother-Nielsen O, Levin K, Holst JJ, Beck-Nielsen $\mathrm{H}$ : Assessment of hepatic insulin action in obese type 2 diabetic patients. Diabetes 2001;50:1363-1370.

23. Singal P, Muniyappa R, Chisholm R, Hall G, Chen H, Quon MJ, Mather KJ: Simple modeling allows prediction of steadystate glucose disposal rate from early data in hyperinsulinemic glucose clamps. Am J Physiol Endocrinol Metab 2010;298:E229-E236.

24. Ferrannini E, Mari A: How to measure insulin sensitivity. J Hypertens 1998;16:895-906.

25. Banerjee D, Vikram N, Mishra P, Bhatt R, Prakash S, Misra A: Correlation of a $\left[{ }^{13} \mathrm{C}\right]$ glucose breath test with surrogate markers of insulin resistance in urban and rural Asian Indians. Metab Syndr Relat Disord 2009;7:215-219.

26. Ibarra-Pastrana E, Candia Plata Mdel C, Alvarez G, Valencia ME: Estimation of insulin resistance in Mexican adults by the $\left[{ }^{13} \mathrm{C}\right]$ glucose breath test corrected for endogenous total $\mathrm{CO}_{2}$ production. Int J Endocrinol 2012;2012:907818.

27. Barth E, Tugtekin I, Weidenbach H, Wachter U, Vogt J, Radermacher P, Adler G, Georgieff M: Determination of ${ }^{13} \mathrm{CO}_{2} /{ }^{12} \mathrm{CO}_{2}$ ratio by IRMS and NDIRS. Isotopes Environ Health Stud 1997;33:209-213.

28. Schadewaldt P, Schommartz B, Wienrich G, Brosicke $H$, Piolot R, Ziegler D: Application of isotope-selective nondispersive infrared spectrometry (IRIS) for evaluation of $\left[{ }^{13} \mathrm{C}\right]$ octanoic acid gastric-emptying breath tests: comparison with isotope ratio-mass spectrometry (IRMS). Clin Chem 1997;43:518-522.

Address correspondence to: Kieren J. Mather, MD, FRCPC Indiana University School of Medicine 541 North Barnhill Drive, Room CL365

Indianapolis, IN 46202

E-mail: kmather@iu.edu 